\title{
Commentary on "surgical management of zygomatic complex fractures in a major trauma centre"
}

\author{
Francesco M. Egro, Anisha Konanur, Guy M. Stofman \\ Department of Plastic Surgery, University of Pittsburgh Medical Center, Pittsburgh, PA 15261, USA.
}

Correspondence to: Dr. Francesco M. Egro, Department of Plastic Surgery, University of Pittsburgh Medical Center, 3550 Terrace Street 6B Scaife Hall Pittsburgh, Pittsburgh, PA 15261, USA. E-mail: francescoegro@gmail.com

How to cite this article: Egro FM, Konanur A, Stofman GM. Commentary on "surgical management of zygomatic complex fractures in a major trauma centre". Plast Aesthet Res 2019;6:15. http://dx.doi.org/10.20517/2347-9264.2019.31

Received: 25 Jun 2019 Accepted: 10 Jul 2019 Published: 23 Jul 2019

Science Editor: Raúl González-García Copy Editor: Jia-Jia Meng Production Editor: Jing Yu

Zygomatic complex (ZMC) fractures are one of the most common facial fractures seen in trauma centers. The zygomatic bone has a quadrilateral shape with several processes that articulate with the frontal bone [via frontozygomatic (ZF) suture], the maxilla [via zygomaticomaxillary (ZM) buttress], the temporal bone [via zygomaticotemporal (ZT) suture], and the greater wing of the sphenoid bone within the orbit via zygomaticosphenoid suture. These four processes work to stabilize the position of the face with respect to the cranium and provide definition of facial width and midface projection. Fractures of the zygomatic bone often occur at these four suture sites resulting in ZMC fractures rather than fracture of the zygomatic bone alone. The management of ZMC fractures are usually of aesthetic nature except in two occasions. First, when the fracture impinges on the mandibular coronoid process, resulting in a restriction of mandibular movements and trismus ${ }^{[1]}$. Second, ZMC fractures can disrupt the orbit foundation enough to cause ophthalmoplegia, diplopia, malposition of the globe, sensory deficits along distribution of the infraorbital nerve, or palpable irregularities of the lateral and inferior orbital rim $^{[1,2]}$.

Surgical intervention of ZMC fractures require open reduction and internal fixation of the points of the tetrapod. Fracture fixation may be broadly classified by open reduction with anterior approach or an open reduction with anterior and posterior approach. The anterior approach involves up to three incisions, one for each suture in the tetrapod except for the ZT suture ${ }^{[2]}$. For access to the ZF suture and lateral orbital wall, the upper blepharoplasty incision allows for less scarring and better surgical access to the region in comparison to the lateral brow approach or use of the current laceration ${ }^{[3]}$. The transconjuctival incision is preferred for access to the infraorbital rim, however, it must also be noted that the lower-lid approach is not without significant risks, such as the possibility of lower-lid malposition and external lid scarring ${ }^{[3]}$.

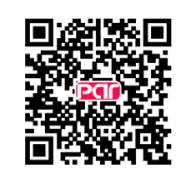


Finally, a gingivobuccal sulcus incision effectively exposes the maxilla for reduction and stabilization of the ZM buttress with aesthetically pleasing postoperative results ${ }^{[4]}$. Historically, with the anterior approach, ZMC fractures required fixation of all three anatomical positions. However, recently there has been a trend toward fixation of fewer points depending on severity of injury.

The authors present a retrospective study analyzing the epidemiology and surgical management using open-reduction and internal fixation of 27 isolated ZMC fracture cases in Kings College London Hospital during 2016. Average time between fracture and surgical intervention was 15 days. They found one-point fixation was the most popular technique for surgical stabilization of zygomatic fractures, with the ZM buttress as the most common fixation point. The authors described that sufficient stability was achieved with one-point fixation when there is no comminution of the ZMC fracture. The authors concluded that there is a lack of consensus in the repair methodology of ZMC fractures likely due to surgeon preference, training, and experience.

Despite the efforts by the authors to assess the surgical management of ZMC fractures in their major trauma center and compare those findings with the literature, there are certain limitations that readers should consider when interpreting the results of this study. Firstly, edema after injury makes the exposure of the ZMC fractures challenging and for this reason many surgeons advocate to wait for the edema to decrease before operating. However, within fifteen days the fracture is often viscous in touch and difficult to maneuver ${ }^{[5]}$. From our experience, five to seven days after the onset of the fracture has shown to be ideal time and we believe that waiting 15 days as highlighted in this paper might be too long.

Secondly, we do not agree that one-point fixation provides sufficient stability of the fracture and instead recommend two or three-point fixation, due to multiple variables that can influence the fracture's healing process. For example, the masseter pull on the zygoma could potentially displace the malar fragments. This is particularly important to take note of in a comminuted zygomatic fracture in which masseter forces could displace the segments and have suboptimal aesthetic outcomes when set ${ }^{[6]}$. Previous literature has described that two-point or three-point fixation techniques of ZMC fractures provide more stability when compared to one-point fixation ${ }^{[2,7-9]}$. A meta-analysis of randomized control trial data done by Jazayeri et al. ${ }^{[10]}$ suggests that three-point fixation of ZMC fractures are superior, however, when two-point fixation appears to provide stable fixation, potential benefits of a third fixation point should be weighed against costs such as operative time and morbidity of additional incision.

The authors' did not discuss the posterior approach to ZMC fractures, which involves open reduction and fixation of the zygomatic arch. This can be achieved with a coronal approach, where the entire zygomatic arch can be visualized while protecting the frontal branch of the facial nerve. Fractures with extreme posterior displacement, and those with lateral displacement of the zygomatic arch benefit from this approach. Benefits of the coronal incision include exposure of the entire zygomatic arch and roof of the glenoid fossa which allows for precise zygomatic arch reconstruction, eliminating the need for an upper blepharoplasty or lateral brow incision by exposing the ZF suture. Additionally, the bicoronal approach not only provides improved contour of the zygomatic arch/ZMC fractures but also provides access to other facial fractures like the naso-orbital ethmoid, frontal sinus, and superior and lateral orbits ${ }^{[1]}$.

Alternatives to the coronal approach to zygomatic arch repair include the Gillies approach, which is a temporal approach for reduction only of zygomatic arch fractures ${ }^{[2]}$. In this study, the Gillies approach was used for the majority (85\%) of the 13 isolated zygomatic arch fractures in this trauma center. However, based on our experience the Gillies approach produces less than ideal results in ZMC fractures and should be used for isolated zygomatic arch fractures. Results with this approach never fully project the malar eminence back to pre-morbid state, often resulting in a persistent depression of the lateral cheek. In 
complex cases where the zygoma is comminuted in ZMC fractures, we advocate for the use of a bicoronal approach to re-establish adequate anteroposterior projection and width of the face.

Lastly, despite ones best efforts of improving the aesthetic contour by fixating the ZMC fractures, some postoperative asymmetry may persist. We believe that autologous fat grafting (AFT) plays a crucial role in the secondary reconstruction of facial deformities and an increasing level of evidence demonstrates its benefits. In a prospective study of AFT for posttraumatic and postsurgical craniofacial deformities, Bourne et al. ${ }^{[1]}$ demonstrated that AFT provides a safe and minimally invasive alternative to traditional methods (such as regional flaps and prostheses) to restore normal and symmetric facial morphology. AFT allows for better control of tissue volume and improves the quality of scarring and skin. The study concluded that for craniofacial defects, AFT is predictable and effective and reaching volume stability at 3 months.

Ongoing lack of consensus of the surgical management of ZMC fractures makes it challenging to develop a widely accepted treatment protocol. We commend the authors for this study and look forward to future research to evaluate optimal management of ZMC fractures.

\section{DECLARATIONS}

\section{Authors' contributions}

Made substantial contributions to this review of the literature as well as the writing of the commentary: Egro FM, Konanur A, Stofman GM

\section{Availability of data and materials}

Not applicable.

\section{Financial support and sponsorship}

None.

\section{Conflicts of interest}

All authors declared that there are no conflicts of interest.

\section{Ethical approval and consent to participate}

Not applicable.

\section{Consent for publication}

Not applicable.

\section{Copyright}

(c) The Author(s) 2019.

\section{REFERENCES}

1. Marcus JR, Erdmann D, Rodriguez ED. Essentials of craniomaxillofacial trauma. Louis, Mo: Quality Medical Pub; 2012.

2. Neligan P, Warren RJ, Van Beek A. Plastic surgery [still image]. London: Elsevier; 2018.

3. Lee EI, Mohan K, Koshy JC, Hollier LH Jr. Optimizing the surgical management of zygomaticomaxillary complex fractures. Semin Plast Surg 2010;24:389-97.

4. Ji SY, Kim SS, Kim MH, Yang WS. Surgical Methods of Zygomaticomaxillary Complex Fracture. Arch Craniofac Surg 2016;17:20610.

5. Strong EB, Gary C. Management of Zygomaticomaxillary Complex Fractures. Facial Plast Surg Clin North Am 2017;25:547-62.

6. Kelley P, Hopper R, Gruss J. Evaluation and treatment of zygomatic fractures. Plast Reconstr Surg 2007;120:5S-15S.

7. Kim JH, Lee JH, Hong SM, Park CH. The effectiveness of 1-point fixation for zygomaticomaxillary complex fractures. Arch Otolaryngol Head Neck Surg 2012;138:828-32. 
8. Papel ID. Facial plastic and reconstructive surgery [still image]. New York: Thieme; 2016.

9. Thorne C, Chung KC, Gosain A, Guntner GC, Mehrara BJ. Grabb and Smith's plastic surgery. 7th ed. Philadelphia: Wolters Kluwer/ Lippincott Williams \& Wilkins Health; 2014.

10. Jazayeri HE, Khavanin N, Yu JW, Lopez J, Shamliyan T, et al. Fixation Points in the Treatment of Traumatic Zygomaticomaxillary Complex Fractures: A Systematic Review and Meta-Analysis. J Oral Maxillofac Surg 2019. Epub ahead of print DOI: 10.1016/ j.joms.2019.04.025.

11. Bourne DA, Bliley J, James I, Donnenberg AD, Donnenberg VS, et al. Changing the Paradigm of Craniofacial Reconstruction: A Prospective Clinical Trial of Autologous Fat Transfer for Craniofacial Deformities. Ann Surg 2019. Epub ahead of print DOI: 10.1097/ SLA.0000000000003318. 